\title{
Factors of Code-Switching among Bilingual International Students in Malaysia
}

\author{
Paramasivam Muthusamy ${ }^{1}$, Rajantheran Muniandy ${ }^{2}$, Silllalee.S.Kandasamy ${ }^{3}$, Omrah Hassan@ Hussin ${ }^{1}$, Manimaran \\ Subramaniam $^{2} \&$ Atieh Farashaiyan ${ }^{4}$ \\ ${ }^{1}$ Department of Foreign Languages, University Putra Malaysia, Malaysia \\ ${ }^{2}$ Department of Indian Studies, Universiti Malaya, Malaysia \\ ${ }^{3}$ Department of Modern Languages, Universiti Tunku Abdul Rahman, Malaysia \\ ${ }^{4}$ Department of Foreign Languages \& Linguistics, Shiraz University, Iran \\ Correspondence: Rajantheran Muniandy, Department of Indian Studies, Faculty of Arts and Social Sciences, \\ Universiti Malaya, Malaysia.
}

Received: March 23, 2020

Accepted: July 20, 2020

Online Published: July 21, 2020

doi:10.5430/ijhe.v9n4p332

URL: https://doi.org/10.5430/ijhe.v9n4p332

\begin{abstract}
The present study aims to identify the factors that can potentially affect code switching in a college classroom in Malaysia. The participants were twenty bilingual international students enrolled in an English course in Malaysia. The data were collected through semi-structured interviews with the participating students. The findings of the study indicated that the main factor behind code switching among the students was incompetence in the second language. Other factors that could account for code switching were maintaining privacy, the ease of speaking in the first language compared to speaking in English, avoiding misunderstanding, and unfamiliarity with similar words in English. Therefore, code switching was found to be an effective strategy used by the students to make their intended meaning explicit and to transmit some knowledge to other students in classroom interactions. This study provides some implications for English teaching community including language learners, teachers, and curriculum developers.
\end{abstract}

Keywords: code switching, bilingual, English as second language, international students

\section{Introduction}

\subsection{Background of the Study}

Individuals who have acquired two languages reveal an attention-grabbing phenomenon acknowledged as 'code switching". Code switching is described as the combining terms or phrases from two languages together through the duration of speaking or writing (Al-Qaysi, 2019). In this regard, a language or a dialect is considered a 'code'. Code switching (CS) is the change of terms and expressions between two languages. This frequently happens between individuals who share those specific codes (Basabrin, 2019).

One of the primary definitions of CS was provided by Weinreich (1986,p.87) in his description of bilingualism as "the practice of alternately using two languages". Marasigan (1983) stated that code switching occurs when two languages are used in the same sentence. In an earlier study, Bokomba (1989, p.198) claims that "CS is the mixing of words, phrases and sentences from two distinct grammatical (sub) systems across sentence boundaries within a speech event". In addition, Myers-Scotton (2002) suggested that the elements of two language varieties occur in the same place where one of the languages functions as the morphosyntactic structure of the code switching.

CS assumes different forms. It may occur at the beginning, middle, and at the end of a sentence. CS is divided into inter-sentential switching and intra-sentential switching (Myers-Scotton, 2012). In intersentential code switching, a language element is switched at sentence borders. This type of switching is exchanged mainly between competent bilingual speakers. However, in intrasentential code switching, the shift occurs in the middle of a sentence with no interruptions, hesitations, or pauses to show a shift (Lipski, 1985). Intersentential CS is referred to as mechanical CS which occurs unintentionally compensating for unknown or unavailable terms in one language. CS is another term used to refer to this type of CS. Another class of CS (code changing) occurs through fluent intrasentential shifts, 
which transfers the focus from one language to another. Code changing is influenced by situational and stylistic factors and the switch occurs between two languages consciously and intentionally (Lipski, 1985).

In classes with students from different language backgrounds, code switching is extensively observed. Bilinguals from different language backgrounds shift their languages easily at diverse subjects in speaking or in writing. Individuals frequently change their language in the flow of their everyday exchanges (Cahyani et al., 2018). Many fluent educated English speakers frequently change their language through incorporating English expressions, phrases or sentences into their interactions. There is always a cause for the occurrence of code-switching although it may be done unconsciously. Some socio-linguistic variables determine it. It is extensively employed in societies which have diverse languages and cultures (Fachriyah, 2017; Paramesravan \& Lim, 2018).

In some Asian countries including China, India, Malaysia, and Pakistan, bilingual speakers typically learn English and use it as their second language (L2) while their first language (L1) is their mother language and is the dialect of the area (Song, 2019). Consequently, code-switching as a communal process where English and other languages (codes) are intermingled in phrases is very common in these societies. In the context of Malaysia, observing the code-changing is very prevalent. For example, in conversations when there are many English words since the Malay language or another code is prevailing and vice versa (Xiaofang, 2017).

\subsection{Statement of the Problem}

In classes held at universities, code switching occurs in both teachers' and students' interactions and discourse (Sert, 2016). ESL teachers, linguistics, and researchers argue that code switching is not essentially a hindrance or deficiency in the interlanguage system. Bilingual speakers switch languages alternatively for various reasons during their conversations and interactions. Scholars are interested in code switching to reveal why individuals who are proficient in two languages often tend to use words or phrases from both languages alternatively in a particular situation (Luo, 2019; Shanehsazzadeh \& Heidari Darani, 2017).

Despite the extensive studies conducted on code switching, researchers have not investigated the factors affecting code switching used by bilingual international students learning English as a foreign or second language. (Bhatti1 et al., 2018). Investigating factors and reasons behind code switching in the Malaysian context is important due to the fact that because of the bilingual education system and patterns used in multilingual communication in Malaysian community, speakers are very likely to know and speak more than one language. This being so, CS is more likely to be used by speakers having various social backgrounds in order to get their massage communicated successfully.

\subsection{Research Objective and Research Question}

The focus of this study is on identifying factors that might influence code switching used by bilingual international students attending a college classroom in Malaysia. More specifically, this study tries to answer this question:

What are the factors that might influence code switching among bilingual international students in a college classroom in Malaysia?

\section{Methodology}

\subsection{Research Design}

The current study used a mixed-method design. The mixed-method design is categorized into the explanatory design, exploratory design, and triangulation design (Lodico, Spaulding, \& Voegtle, 2016). Among the mentioned designs, the present study employed an exploratory design in which the data are first transcribed, collected, and analyzed qualitatively and then assessed quantitatively by calculating the frequency of occurrences.

\subsection{Participants of the Study}

The participants in this study included 20 bilingual international students (15 graduate and 5 undergraduate students) enrolled in a language college in Malaysia. All of the participants were from different countries having various cultural and linguistic backgrounds. The participants were from different nationalities including African-English, Arab- English, Chinese-English, and Korean-English bilinguals. The participants' age varied from 19 to 31 . Among them, ten of them were males and another ten were females.

\subsection{Data Collection}

Data were collected through the use of semi-structured interviews. Participants were informed that their interviews were recorded only for the purposes of the research and their names were kept confidential by the researchers. Students voluntarily choose to participate in the interview and they were given enough time to express their views, 
opinions and arguments. A total of 400 minutes of interviews with the students were gathered. The interview was carried out in the English language.

\subsection{Data Analysis \& Interpretation}

The data collected were first transcribed. Then, a qualitative analysis was carried out. In doing so, a thematic analysis was run based on Braun and Clarke's (2006) analytical procedure. To do so, the transcribed interviews were read and re-read several times to identify the gathered data. In the next stage, the identified data were placed into meaningful titles or sub-titles. In the third phase, the codes were analyzed and mixed to form related categories. The formed categories were reviewed and refined in the fourth phase to form a satisfactory thematic map for use in the study. The process continued in the next phase and the categories were redefined and refined further to make sure each identified category can capture and analyze the data efficiently.

Neuman (2014) suggested that quantitative analysis involves using numerical data to extract meanings. After performing the quantitative analysis of the data collected in this study, the findings were calculated manually and presented as frequencies and percentages in a table. Furthermore, the geographical dispersion of the data was displayed graphically.

\section{Results and Discussion}

According to the results of the analysis, the participants stated different reasons for why they resorted to code switching in their interactions. Factors affecting code switching extracted from the interviews with the participants are as follows: a) The lack of competence in the second language, b) Preserving privacy, c) The ease of speaking in one's own language, d) Avoiding ambiguity and misunderstanding, e) The lack of similar words in English, f) Unawareness of the equivalent English term or phrase, g) Bridging the gaps while speaking, h) Showing intimacy, i) Adding emphasis, j) Drawing attention, and k) pragmatic reasons. The table below shows different social factors accounting for the use of code switching identified in the dataset under analysis.

Table 1. Factors for Code-Switching Among Bilingual English Students

\begin{tabular}{lll}
\hline Factors & Number & Percent \\
\hline Lack of competence in L2 & 15 & $26 \%$ \\
Mintaining privacy & 1 & $2 \%$ \\
Easier to speak in their own language & 7 & $12 \%$ \\
avoiding misunderstanding & 3 & $5 \%$ \\
Not knowing the English word & 10 & $19 \%$ \\
filling the gap in speaking & 5 & $7 \%$ \\
conveying intimacy & 4 & $6 \%$ \\
adding emphasis & 2 & $4 \%$ \\
attracting attention & 6 & $10 \%$ \\
pragmatic reasons & 5 & $9 \%$ \\
Total & 58 & $100 \%$
\end{tabular}

The frequency of different lingiuistic factors mentioned by participants in their interviews is displayed in the table. As it can be seen, Lack of L2 competence is a factor accounting for $26 \%$ of the cases (58 cases in total) where code switching was used by the participants in different contexts, followed by Not knowing the English word accounting for $19 \%$ of the code-switched elements identified in the data. As displayed in the table, the next most social factors behind the use CS in the present study are as follows: Easier to speak in their own language (12\%), attracting attention (10\%), pragmatic reasons (9\%), filling the gap in speaking (7\%), conveying intimacy (6\%), avoiding misunderstanding (5\%), emphasising a point (4\%), and maintaining privacy (2\%) respectively.

\subsection{Lack of L2 Competence}

In the interview students were asked: "why did you switch the codes in class?" The majority of the participants (15 out of 20) reported that they do not have enough linguistic competence in the second language. In other words, they do not have enough language proficiency. Therefore, lack of learners' literacy in L2 is found to be the first and most dominant factor for code-switching among the participants. One student mentioned, "I do not have sufficient knowledge in the English, so I sometimes change to my mother tongue". 


\subsection{Lack of Vocabulary Knowledge in the English}

The second noticeable factor in the data reported is lack of English vocabulary knowledge. Most of the students declared that they do not know the English words. Therefore, they have to code switch to their mother tongue or their first language. A majority of the participants stated that code switching make the class climate more interesting when the class is boring. Since many students from various countries used to speak English with accents it created a degree of misunderstanding making them laugh at one another.

\subsection{Ease to Speak in L1}

The results of data analysis suggested that the third most frequently observed factor was the ease of speaking in the first language (L1). Accordingly, $12 \%$ of the participants stated that they were more comfortable when speaking in their own language compared to speaking in English. One student stated that when he spoke English his Korean friend did not understand him because of his accent. He also stated that he did not understand Chinese when it was spoken with an accent. As a result, he favored speaking in his own language.

\subsection{To Attract Attention}

Another factor mentioned by participants is attracting others' attention in the speaking. About $10 \%$ of interviewees talked about this factor. For example, one student declared, "I use the English word Hello everyone at the beginning of my sentence to attract watchers' attention. Then, I switch to my mother tongue.

\subsection{Pragmatic Reasons}

It is assumed that speakers may resort to code switching in order to draw attention to the conversational context because alternating between two languages is at times highly meaningful. Besides, $9 \%$ of the participants stated the pragmatic reasons as one of the main factors behind their code switching.

\subsection{To Fill the Gap in Speaking}

The participants stated that during conversations out of the classroom, they compensated for the stopgaps and interruptions using their native language. To avoid gaps in communication, code switching was used by the students as a compensatory strategy for the lack of fluency in the target language. Accordingly, $7 \%$ of the participants mentioned 'to fill a gap' as a reason for resorting to code switching.

\subsection{To Convey Intimacy}

The next important factor that a number of the students referred to was conveying intimacy. Among the interviewees, four of them emphasized the importance of this factor in switching their language to another one.

\subsection{To Avoid Misunderstanding}

In addition, $5 \%$ of the participants stated that they used to code switch to avoid misunderstanding when they did not know the equivalent terms or phrases in English. Another reason is that the students were not as fluent in speaking English, as the second language they were learning, compared to their mother tongue. The participants with less proficiency in the second language competence always had problems in finding L1 and L2equivalences. Therefore, they used the native equivalent of a given lexical item, switching to their native language while speaking in the second language. This was mainly observed among students who were learning a second language, which can be attributed to the linguistic incompetence in speaking the new language. As such, equivalence seeking factor gives the student the chance of maintaining communication by filling the gaps created by second language incompetence.

\subsection{To Emphasize a Point}

Another factor affecting students' resort to code switching was 'to add emphasis' which is considered a very significant factor in linguistic study. Only $4 \%$ of the participants stated that they stated that they used code switching to add emphasis. Accordingly, the students repeated the message to be communicated in the target language in their mother tongue in their attempt to give the meaning by using a repetition technique. Repetition as a specific case of language alternation is used for two purposes: First, the student may not have communicated the meaning they intended accurately in the target language. Besides, the student may consider that they used code switching to communicate the message more clearly. The participants also stated that repetition as a code switching strategy was used to make their speech seem fashionable or to 'add emphasis' in the second language so that the addressee would capture what they say and be impressed. 


\title{
3.10 To Maintain Privacy
}

The least noticeable factor of code switching is to maintain privacy. Only one participant mentioned this factor in his interview. One of the participants stated that he switched the code in the classroom so that other classmates would not understand is the thing he was conveying with friends from the home country.

In summary the study revealed that the factors that influenced code-switching were Lack of L2 competence (26\%), Not knowing the English (19\%) Easier to speak in their own language (12\%), attracting attention (10\%), pragmatic reasons (9\%), filling the gap in speaking (7\%), conveying intimacy (6\%), avoiding misunderstanding (5\%), emphasising a point (4\%), and maintaining privacy (2\%) respectively.

\section{$26 \%$}

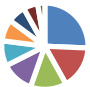 \\ - Lac of vocabulary knowledge in English \\ - Ease of speaking in L1 \\ - Attracting attention \\ - Pragmatic resources \\ - Filling the gap in speaking
}

\section{Conclusions and Implications}

The findings from this study indicate that the main factor accounting for code switching in the international classroom studies is the lack of competence in the second language. Other noted factors were: Not knowing the English, Easier to speak in their own language, attracting attention, pragmatic reasons, filling the gap in speaking, conveying intimacy, avoiding misunderstanding, emphasizing a point and maintaining privacy respectively. Accordingly, it can be concluded that code switching is a natural portent observed among bilingual foreign students. The participants in this study agreed they switch the codes for different reasons. The frequency of each reason for resorting to code exchange was not the same among the participants.

Other factors underlying the use of code switching showed some variations based on the students' needs, locations, settings, intentions or purposes. Other factors such as the inability to communicate in a new international cultural setting, the assimilation of new foods, and unfamiliar cultural behavior were also considered to be effective in code switching. However, all these factors seem to be somewhat effective for second language acquisition for bilingual international students in an international classroom context. In the same vein, Skiba (2012) argued that one of the factors accounting for code switching is the student's inability to express themselves and get their message communicated in language classrooms and code switching contribute to maintaining the continuity in speech and it does not interfere with the flow of linguistic expression. This being so, code switching can be regarded as a supporting component contributing to communicating information in social interactions. As a result, code switching improves communication as a tool for used for conveying meaning.

This study has some implications for language learning as it demonstrates code switching as a useful component in adult language learning classroom. In their teaching philosophy, language teachers should know that codes emerge from bilingual interactions and they serve as very useful tools for communicating the message of the lesson if they are used properly in the discourse. In many situations, a teacher may ask students to switch codes as an effective strategy for mastering the target language. (Köylü, 2018). Code exchange in some situations may produce an unharmonious association between speakers and the language community, because code switching words and expressions may not have same value, status, and functions in speakers' cultures

(Grant \&Nguyen, 2017). For instance, in some cultural contexts, local languages may be regarded as inferior when they are used in familiar and informal communication. Other times, learners' focus is on getting the best possible answer in English class to show they have mastered it. (Onga \& Zhang, 2018). 
Code switching may be also employed in an English immersion context where it enhances clarification when a word or phrase is unknown. The use of code exchange is welcomed in the classroom as it may enhance English competency if it does not occur excessively. Besides, if the language teacher has some familiarity with students' first language, he/she may handle the lessons more effectively (García et al., 2018). In sum, code switching can serve as a useful strategy in classroom interactions if the aim is to get the intended meaning communicated more clearly and to transfer the knowledge to students in a more efficient way.

\section{Suggestions for Future Research}

This study identified the factors that affect code switching in the college classroom in Malaysia. Other studies can do this study in another setting such as the university. In addition, other studies can be conducted in order to make use of other data collection methods. This research has a number of limitations. One of them is the use of ust one data collection method. Another limitation is the number of interviewees.

\section{References}

Al-Qaysi, N. (2019). Students and educators' attitudes towards code-switching: A longitudinal study. International Journal of Information Technology and Language Studies, 3(2), 61-72.

Aisha Bhatti1 , Sarimah Shamsudin1 \& Seriaznita Binti Mat Said. (2018). Code-Switching: A Useful Foreign Language Teaching Tool in EFL Classrooms. ELT Journal, 11(6), 93-101. https://doi.org/10.5539/elt.v11n6p93

Auer, P. (Ed.) (1998). Code-switching in conversation: Language, interaction and identity. London: Rutledge.

Ayeomoni, M. (2006). Code-switching and code-mixing: Style of language use in childhood in Yoruba speech community. Nordic Journal of African Studies, 15 (1), 90-99.

Baker, C. (2000). Foundations of bilingual education and bilingualism. Third Edition. Clevedon: Multilingual Matters.

Basabrin, A. (2019). Code-switched greeting by bilingual Saudi-American subject: A case study. Arab World English Journal, 10(1), 335-346. https://doi.org/10.24093/awej/vol10no1.28

Bokomba, E. (1989). Are there syntactic constraints in code-mixing? World Englishes, 8(3), 277-292. https://doi.org/10.1111/j.1467-971X.1989.tb00669.x

Cahyani,H., Courcy, M, \& Barnett,. (2018). Teachers' code-switching in bilingual classrooms: exploring pedagogical and sociocultural functions. International Journal of Bilingual Education and Bilingualism, 21(4), 465-479. https://doi.org/10.1080/13670050.2016.1189509

Chan, B. (2003). Conversational code switching and relevance theory. International Pragmatic Association Journal, $12(3), 34-8$.

Fachriyah, E. (2017). The function of code switching in an English Language Classroom. Sielle Journal, 4(2), 148-156. https://doi.org/10.24815/siele.v4i2.6327

García, P. B., Leibold, L., Buss, E., Calandruccio, L., \& Rodriguez, B. (2018). Code-switching in highly proficient Spanish/English bilingual adults: Impact on masked word recognition. Journal of Speech, Language, and Hearing Research, 61(9), 2353-2363. https://doi.org/10.1044/2018_JSLHR-H-17-0399

Gumperz, J. (Ed.) (1982). Language and social identity. Cambridge: CUP. https://doi.org/10.1017/CBO9780511620836

Kothari, C. R. (2014). Research Methodology: Methods \& Techniques. New Delhi: New Age International.

Köylü, Z. (2018). The Use of L1 in the Tertiary L2 Classroom: Code-switching Factors, Functions, and Attitudes in Turkey. Electronic Journal of Foreign Language Teaching, 15(2), 271-289.

Lodico, M. G., Spaulding, D. T., \& Voegtle, K. H. (2016). METHODS IN EDUCATIONAL RESEARCH: From Theory to Practice. San Francisco: Jossey-Bass.

Lipski, J. (1985). Linguistic aspects of Spanish-English language switching. Arizona: Center for Latin American Studies.

Grant, L.., \& T Nguyen, T. H. (2017). Code-switching in Vietnamese university EFL teachers' classroom instruction: a pedagogical focus. Language Awareness, 26(3), 244-259. https://doi.org/10.1080/09658416.2017.1402915

Marasigan, E. (1983). Code-switching and code-mixing in multilingual societies. Singapore: Singapore University Press. 
Muthusamy, P. (2009). Communicative functions and reasons for code switching: A Malaysian perspective. Language \& Society, 5, 1-16.

Myers-Scotton, C. (2002). Contact linguistic: Bilingual encounters and grammatical outcomes. New York: Oxford University Press.

Neuman, W. L. (2014). Social Research Methods: Qualitative and Quantitative Approaches. England: Pearson.

Wee Ong, ., \& Zhang, L. . (2018). The effects of code-switched reading tasks on late-bilingual EFL learners' vocabulary recall, retention and retrieval. System, 72, 13-22. https://doi.org/10.1016/j.system.2017.10.008

Paramesravan, M.D., \& Lim, J.W. (2018). Code-switching practices in a Malaysian multilingual primary classroom from teacher and student perspectives. Indonesian Journal of Applied Linguistics, 8(2), 254-264. https://doi.org/10.17509/ijal.v8i2.13273

Reyes, I. (2004). Functions of code-switching in school children's conversations. Bilingual Research Journal, 28(1), 77-96. https://doi.org/10.1080/15235882.2004.10162613

Skiba, R. (1997). Code switching as a countenance of language interference. The Internet TESL Journal. Retrieved March 3, 2008 from.

Sert, O. (2006). The factors of code switching in ELT classrooms. The Internet TESL Journal. Retrieved March 4, 2008 from http://iteslj.org/Articles/SertCodeSwitching.html

Song, J. (2019). Language socialization and code-switching: a case study of a Korean-English bilingual child in a Korean translational family. International Journal of Bilingual Education and Bilingualism, 22(2), 91-106. https://doi.org/10.1080/13670050.2016.1231165

Weinreich, U. (1986). Languages in contact. The Hague: Mouton.

Xiaofang, Q. (2017). Pedagogic and Social Functions of University EFL Teachers' Classroom Codeswitching. International Journal of Language and Linguistics, 5(6), 179. https://doi.org/10.11648/j.ijl1.20170506.13 